ORIGINAL ARTICLE

\title{
Attendance at a hospital emergency department by drivers involved in automobile accidents in Italy
}

\author{
C Pileggi, G Nicotera, I F Angelillo
}

Emerg Med J 2005;22:246-250. doi: 10.1136/emj.2004.018390

See end of article for authors' affiliations ......................

Correspondence to: Dr I F Angelillo, Chair of Hygiene, Medical School, University of Catanzaro "Magna Græcia", Via Tommaso Campanella, 88100 Catanzaro (Italy); angelillo@unicz.it

Accepted for publication 20 October 2004
Objective: This study investigated the profile of drivers involved in automobile accidents attending a hospital emergency department (ED) in Catanzaro (Italy).

Methods: Car drivers involved in automobile accidents who were registered for emergency care between May 2003 and February 2004 were included in the study. Demographics and details of the accident were collected immediately after admittance, before examination by the medical staff. For each patient, the medical staff completed a form including diagnostic investigations and medical/surgical examination in the ED.

Results: Of a total of 424 drivers included in the study $27.4 \%$ had conditions that were definitely nonurgent problems. Multiple logistic regression analysis indicated that the use of the ED as a source of nonurgent care was significantly higher among patients who were driving at a lower speed when the accident occurred, among those who presented to the ED before the implementation of the new Italian traffic code, and among those who underwent fewer diagnostic investigations and medical/surgical examinations in the ED. Most of the automobile related lesions occurred in the neck $(43.9 \%)$ followed by multiple body regions (12.5\%) and the upper extremities (10.4\%). According to the nature of the injury a third were contusions (34\%), followed by pain without physical signs and symptoms $(28.8 \%)$, and dislocation, sprains, and strains (22.9\%).

Conclusions: Development of health promotion and education campaigns is required to prevent the use of the ED as a source of non-urgent care by those involved in automobile accidents.
A utomobile related mortality and morbidity remain a major problem for the public health sector in most developed and developing countries because of the high proportions of injuries. In Italy, road traffic accidents are the third highest cause of mortality in the general population. Between 1994 and 2002, the number of incidents and those injured as the result of motor vehicle accidents increased from around 170000 to 237000 and from 239000 to 338000 respectively. The reduction of mortality due to road traffic accidents is lower than average when compared with European figures. ${ }^{1}$

In Italy, a new traffic code aimed at influencing attitudes towards driving behaviours has been introduced for the purpose of saving lives and reducing injuries to drivers and passengers of vehicles involved in road traffic accidents. ${ }^{2}$ Specific actions include speed control, crackdown on drunken driving, and mandatory use of safety equipment with severe penalties for non-users. This new traffic code with accompanying penalties has been widely publicised through the mass media.

Several issues remain partially unresolved in the existing literature about automobile accidents, in particular the impact of the extent and consequences of trauma on drivers involved in automobile accidents attending hospital emergency departments. To contribute to a better understanding of the magnitude of automobile trauma, the present epidemiological survey investigated the profile of drivers involved in automobile accidents presenting to a hospital emergency department (ED) in Italy.

\section{MATERIALS AND METHODS}

We collected the data presented in this paper between May 2003 and February 2004 in the ED of a general regional 717 bed non-teaching hospital in Catanzaro. The city of Catanzaro is located in the Italian region of Calabria (two million inhabitants) in the extreme southern part of peninsular Italy and has a population of approximately 100000 . Its demographic characteristics are typical of the southern regions of Italy.

A stratified sample of three five-hour sessions was randomly selected in order to include five weekday and two weekend sessions. The sessions were from $9.00 \mathrm{am}$ to $2.00 \mathrm{pm}$, from $3.00 \mathrm{pm}$ to $8.00 \mathrm{pm}$, and from $9.00 \mathrm{pm}$ to 2.00 am for each day of the study period.

Patients awaiting emergency care were eligible for inclusion in the study if they were involved as drivers in automobile accidents. An accident was defined as any incident where an automobile driven by the participant was involved in a collision with another vehicle, object, person, or animal, or where the individual lost control of the vehicle, irrespective of damage or injury. Two medical interviewers, with at least six months experience at the ED, who were not involved in care and had been trained previously, collected the data. All patients who gave written informed consent to participate were interviewed immediately after admittance, before examination by the medical staff at the ED.

The survey questionnaire included items about patients' demographic and socioeconomic characteristics and details of the accident including: how the accident occurred; use of seat belt; speed; time of accident; day of the week; condition of road; weather; arrival time at the ED; means of transportation to the ED; total time driven since the accident; kilometres covered in a year; and when the driver's licence was issued. When patients were not able to take part in the interview because of their health status, their relatives were asked to provide the information. All medical staff at the ED were asked to complete a form for each participating patient including diagnostic investigations, medical/surgical examination, prescriptions, final medical diagnosis, referral, and discharge decisions. 
Injuries to patients involved in car crashes have been classified according to an International Classification of Diseases (ICD)-10 matrix system of codes with several axes representing the location and the nature of injury. ${ }^{3}$ The matrix was modified according to the following groupings: "head" (face and head), "upper extremities" (shoulder, upper arm, elbow, forearm, wrist, and hand); and "lower extremities" (hip, thigh, knee, lower leg, ankle, and foot). Furthermore, we included "pain" with no physical signs or symptoms, severity of injury, and loss of consciousness.

The following definitions of the levels of urgent care were developed before the study was conducted according to the guidelines for the Canadian Emergency Department Triage and Acuity Scale ${ }^{4}$ :

- Level 1 (resuscitation) - conditions that are threats to life or limb (or imminent risk of deterioration) that require immediate aggressive interventions

- Level 2 (emergent)—conditions that are potential threats to life, limb, or function and require rapid medical intervention or delegated acts

- Level 3 (urgent) - conditions that could possibly progress to a serious status requiring emergency intervention, perhaps associated with significant discomfort or dysfunction at work or activities of daily living

- Level 4-(less urgent)—conditions relating to age, distress, or potential for deterioration or complications that would benefit from interventions or reassurance within one to two hours

- Level 5 (non-urgent)—conditions that are acute and nonurgent as well as conditions which may be part of a chronic problem with or without evidence of deterioration. The investigation or interventions for some of these illnesses or injuries could be delayed or even referred to other areas of the hospital or healthcare system

\section{Statistical analysis}

We analysed the data using multiple logistic regression. A model was developed to identify the variables determining the profile of patients who attend the ED for non-urgent care. The explanatory variables included were: age (continuous, in years), sex $(\operatorname{man}=1$, woman $=2)$, type of job (unemployed $=1$, lower managerial $=2$, high professional and managerial $=3$, skilled labourer $=4$ ), weather conditions when the accident occurred (rainy $=0$, clear/cloudy $=1$ ), time of the accident $(8.00 \mathrm{am}-7.59 \mathrm{pm}=0,8.00 \mathrm{pm}-$ $7.59 \mathrm{am}=1$ ), speed when the accident occurred (continuous, in $\mathrm{km} / \mathrm{h}$ ), road classification where the accident occurred (local $=1$, motorway/highway $=2$ ), accident occurred before the implementation of the new traffic code (yes $=0$, no $=1$ ), kilometres covered in a year as a driver of automobile (continuous), day of collision (Monday-Friday $=1$, Saturday-Sunday $=2$ ), seat belt use at the moment of the accident $($ no $=0$, yes $=1)$, and number of diagnostic investigations (continuous) and medical/surgical examination $(0=$ no, $1=$ yes $)$ in the ED. We set the significance level for including variables in the model at $\mathrm{p}=0.2$ and for dropping variables from the model at $\mathrm{p}=0.4$. Adjusted odds ratios (ORs) and 95\% confidence intervals (CIs) were calculated. We analysed the data using the Stata software program.

\section{RESULTS}

A total of 424 drivers, 18 years or older, who registered for care in the ED after a road accident, participated in the study. The demographics of the study population and principal crash related factors are presented in table 1 . The mean age was 36 years (range 18-82), almost two thirds of crashes occurred on local roads, three quarters on weekday, $81.1 \%$

\begin{tabular}{|c|c|c|}
\hline & No & $\%$ \\
\hline \multicolumn{3}{|l|}{ Sex } \\
\hline Men & 253 & 59.7 \\
\hline Women & 171 & 40.3 \\
\hline Age in years & & $36(12.8)^{*}$ \\
\hline$\leqslant 20$ & 35 & 8.3 \\
\hline $21-25$ & 73 & 17.2 \\
\hline $26-30$ & 69 & 16.3 \\
\hline $31-35$ & 51 & 12.0 \\
\hline $36-40$ & 60 & 14.2 \\
\hline $41-45$ & 46 & 10.8 \\
\hline $46-50$ & 25 & 5.9 \\
\hline$>50$ & 65 & 15.3 \\
\hline \multicolumn{3}{|l|}{ Type of job } \\
\hline Employed & 247 & 58.2 \\
\hline Student & 62 & 14.6 \\
\hline Housewife & 52 & 12.3 \\
\hline Unemployed & 48 & 11.3 \\
\hline Retired & 15 & 3.6 \\
\hline \multicolumn{3}{|l|}{ Day of collision } \\
\hline Monday-Friday & 330 & 77.8 \\
\hline Saturday-Sunday & 94 & 22.2 \\
\hline \multicolumn{3}{|l|}{ Time of collision } \\
\hline $8.00 \mathrm{am}-7.59 \mathrm{pm}$ & 344 & 81.1 \\
\hline $8.00 \mathrm{pm}-7.59 \mathrm{am}$ & 80 & 18.9 \\
\hline \multicolumn{3}{|l|}{ Road classification } \\
\hline Local & 288 & 67.9 \\
\hline Motorway/highway & 136 & 32.1 \\
\hline \multicolumn{3}{|c|}{ Seat belt use at the moment of the accident } \\
\hline No & 83 & 19.6 \\
\hline Yes & 341 & 80.4 \\
\hline \multicolumn{3}{|c|}{ Accident occurred before the implementation of the new traffic code } \\
\hline No & 315 & 74.3 \\
\hline Yes & 109 & 25.7 \\
\hline \multicolumn{3}{|l|}{ Weather conditions } \\
\hline Rainy & 104 & 24.5 \\
\hline Clear/cloudy & 320 & 75.5 \\
\hline \multicolumn{2}{|c|}{ Total time of driving before the collision (minutes) } & $31.3(24.1)^{*}$ \\
\hline$<20$ & 204 & 48.1 \\
\hline $20-39$ & 108 & 25.5 \\
\hline$\geqslant 40$ & 112 & 26.4 \\
\hline \multicolumn{3}{|c|}{ Kilometres covered in a year as driver of auto vehicle } \\
\hline$<5000$ & 90 & 21.2 \\
\hline 5000-9999 & 146 & 34.4 \\
\hline $10000-14999$ & 104 & 24.5 \\
\hline$\geqslant 15000$ & 84 & 19.8 \\
\hline \multicolumn{3}{|c|}{ Speed velocity when the accident occurred $(\mathrm{km} / \mathrm{h}) 54.5(26.9)^{*}$} \\
\hline \multicolumn{3}{|c|}{ Mode of transportation to the emergency department } \\
\hline Ambulance & 46 & 10.8 \\
\hline Car driven by patient/on foot & 82 & 19.4 \\
\hline Car driven by other person & 296 & 69.8 \\
\hline
\end{tabular}

between 8.00 am and $7.59 \mathrm{pm}$, and only $10.8 \%$ were brought to hospital by ambulance.

Of the total number of drivers surveyed at the ED, 27.4\%, according to the judgement of the two interviewers, had conditions that were definitely categorised as non-urgent.

Table 2 presents the distribution of urgent and non-urgent visits to the ED according to the various explanatory variables. Non-urgent care was significantly associated with seat belt use at the moment of the accident $\left(\chi^{2}=7.1, \mathrm{df}=1\right.$, $\mathrm{p}=0.008)$, speed when the accident occurred ( $t$ test $=3.97$, $\mathrm{df}=422, \mathrm{p}=0.0001$ ), and whether the accident occurred before implementation of the new traffic code $\left(\chi^{2}=8.68\right.$, $\mathrm{df}=1, \mathrm{p}=0.003)$. The proportion of patients whose visit was considered non-urgent was related to the number of diagnostic investigations in the ED, since the frequency of those undergoing at least one investigation $\left(\chi^{2}=13.56\right.$, $\mathrm{df}=1, \quad \mathrm{p}<0.001) \quad$ or $\quad$ a medical/surgical examination $\left(\chi^{2}=14.31, \mathrm{df}=1, \mathrm{p}<0.001\right)$ was significantly lower in non-urgent patients. The multiple logistic regression analysis partially confirmed the findings of the univariate analysis. Several demographic and crash related variables were 
Table 2 Distribution of urgent and non-urgent visits according to explanatory variables

\begin{tabular}{|c|c|c|c|c|c|}
\hline & \multicolumn{2}{|l|}{ Urgent } & \multicolumn{2}{|c|}{ Non-urgent } & \multirow[b]{2}{*}{ Statistical test results } \\
\hline & Number & $\%$ & Number & $\%$ & \\
\hline \multicolumn{5}{|l|}{ Sex } & \multirow{3}{*}{$\begin{array}{l}\chi^{2}=0.002, d f=1, \\
p=0.96\end{array}$} \\
\hline Men & 184 & 72.7 & 69 & 27.3 & \\
\hline Women & 124 & 72.5 & 47 & 27.5 & \\
\hline Age in years & \multicolumn{2}{|c|}{$36.7(13.4)^{*}$} & \multicolumn{2}{|c|}{$34.2(10.9)^{*}$} & \\
\hline$\leqslant 20^{\prime}$ & 26 & 74.3 & 9 & 25.7 & \\
\hline $21-25$ & 51 & 69.9 & 22 & 30.1 & \\
\hline $26-30$ & 49 & 71.0 & 20 & 29.0 & \\
\hline $31-35$ & 32 & 62.8 & 19 & 37.2 & $t$ test $=1.85, d f=422$, \\
\hline $36-40$ & 43 & 71.7 & 17 & 28.3 & \\
\hline $41-45$ & 36 & 78.3 & 10 & 21.7 & \\
\hline $46-50$ & 17 & 68.0 & 8 & 32.0 & \\
\hline$>50$ & 54 & 83.1 & 11 & 16.9 & \\
\hline \multicolumn{6}{|l|}{ Type of job } \\
\hline Unemployed & 125 & 70.6 & 52 & 29.4 & \multirow{2}{*}{$\chi^{2}=0.62, d f=1, p=0.43$} \\
\hline Employed & 183 & 74.1 & 64 & 25.9 & \\
\hline \multicolumn{6}{|l|}{ Day of collision } \\
\hline Monday-Friday & 235 & 71.2 & 95 & 28.8 & \multirow[t]{2}{*}{$\chi^{2}=1.53, d f=1, p=0.22$} \\
\hline Saturday-Sunday & 73 & 77.7 & 21 & 22.3 & \\
\hline \multicolumn{6}{|l|}{ Time of collision } \\
\hline $8.00 \mathrm{am}-7.59 \mathrm{pm}$ & 246 & 71.5 & 98 & 28.5 & \multirow[t]{2}{*}{$\chi^{2}=1.17, d f=1, p=0.28$} \\
\hline $8.00 \mathrm{pm}-7.59 \mathrm{am}$ & 62 & 77.5 & 18 & 22.5 & \\
\hline \multicolumn{6}{|l|}{ Road classification } \\
\hline Local & 203 & 70.5 & 85 & 29.5 & \multirow[t]{2}{*}{$\chi^{2}=2.10, d f=1, p=0.15$} \\
\hline Motorway/highway & 105 & 77.2 & 31 & 22.8 & \\
\hline \multicolumn{5}{|c|}{ Seat belt use at the moment of the accident } & \multirow{3}{*}{$\begin{array}{l}\chi^{2}=7.10, d f=1 \\
p=0.008\end{array}$} \\
\hline No & 70 & 84.3 & 13 & 15.7 & \\
\hline Yes & 238 & 69.8 & 103 & 30.2 & \\
\hline \multicolumn{5}{|c|}{ Accident occurred before the implementation of the new traffic code } & \multirow{3}{*}{$\begin{array}{l}\chi^{2}=8.68, d f=1 \\
p=0.003\end{array}$} \\
\hline No & 217 & 68.9 & 98 & 31.1 & \\
\hline Yes & 91 & 83.5 & 18 & 16.5 & \\
\hline \multicolumn{6}{|l|}{ Weather conditions } \\
\hline Raining & 71 & 68.3 & 33 & 31.7 & \multirow[t]{2}{*}{$\chi^{2}=1.33, d f=1, p=0.25$} \\
\hline Clear/cloudy & 237 & 74.1 & 83 & 25.9 & \\
\hline $\begin{array}{l}\text { Total time of driving be } \\
\text { (minutes) }\end{array}$ & n 31.912 & & $30(25.4$ & & \\
\hline$<20$ & 141 & 69.1 & 63 & 30.9 & $\chi^{2}=3.29, \mathrm{df}=2, p=0.19$ \\
\hline $20-39$ & 85 & 78.7 & 23 & 21.3 & \\
\hline$\geqslant 40$ & 82 & 73.2 & 30 & 26.8 & \\
\hline Kilometres covered in & er of auto & & & & \\
\hline$<5000$ & 70 & 77.8 & 20 & 22.2 & \\
\hline 5000-9999 & 103 & 70.6 & 43 & 29.4 & $\chi^{2}=1.77, \mathrm{df}=3, p=0.62$ \\
\hline $10000-14999$ & 76 & 73.1 & 28 & 26.9 & \\
\hline$\geqslant 15000$ & 59 & 70.2 & 25 & 29.8 & \\
\hline $\begin{array}{l}\text { Speed velocity when th } \\
\text { occurred }(\mathrm{km} / \mathrm{h})\end{array}$ & $57.7(2)$ & & $46.2(23$ & & $\begin{array}{l}t \text { test }=3.97, d f=422, \\
p=0.0001\end{array}$ \\
\hline Medical or surgical ex & emergenc & epartmer & & & $2^{2}-1331 f_{-1}$ \\
\hline Yes & 141 & 64.7 & 77 & 35.3 & $\chi^{2}=14.31, \mathrm{dt}=1$, \\
\hline No & 167 & 81.1 & 39 & 18.9 & \\
\hline Investigations in the en & ment & & & & \\
\hline$\leqslant 1$ & 247 & 69.2 & 110 & 30.8 & $\begin{array}{l}\chi^{2}=13.56, \mathrm{dt}=1, \\
0<0001\end{array}$ \\
\hline$>1$ & 61 & 91 & 6 & 9 & \\
\hline
\end{tabular}

significantly associated with the use of the ED as a source of non-urgent care. Indeed, the odds of presenting for nonurgent care were significantly higher if patients were driving at lower speeds when the accident occurred (OR $=1.02,95 \%$ CI 1.01 to 1.03) and in those who presented to the ED before the implementation of the new traffic code (OR $=0.51,95 \%$ $\mathrm{CI}=0.28$ to 0.94 ). Moreover, the number of non-urgent visits was related to the number of investigations and examinations in the ED since the odds of being a non-urgent case were significantly higher among those who underwent fewer diagnostic investigations ( $\mathrm{OR}=4.41,95 \% \mathrm{CI}=1.95$ to 10.01 ) and medical/surgical examinations $(\mathrm{OR}=2.82,95 \% \mathrm{CI}=1.75$ to 4.57) (regression model 1 , table 3).

The distribution of patients by location of worst injury is presented in table 4. Most of the automobile related lesions concerned the neck $(43.9 \%)$, followed by multiple body regions $(12.5 \%)$ and the upper extremities (10.4\%). The distribution according to nature of lesions showed that a third were contusions (34\%), followed by pain $(28.8 \%)$, and dislocation, sprains, and strains $(22.9 \%)$. Only four $(0.9 \%)$ and three $(0.7 \%)$ patients had loss of consciousness and injury to internal organs, respectively.

\section{DISCUSSION}

Our study provides an evaluation of the profile of drivers involved in automobile accidents attending an ED.

A possible methodological limitation is the way information was collected, which may affect the interpretation of the results. In particular, the details of the automobile accidents were self-reported and no secondary sources are available to validate or verify the data. Behavioural factors, socially inappropriate and possibly self-incriminating, such as use or disuse of seat belts and high speeds, were possibly underreported and, therefore, their effects could be over or underestimated. However, when respondents are granted anonymity and privacy, self-reported documentation is generally considered sufficiently valid for avoiding the problem of unreliable recall. When respondents believe that 
Table 3 Results of the logistic regression model.

Model 1 Outcome: use of the ED as a source of urgent care

\begin{tabular}{lllll}
\hline Variable & Odds ratio & Standard error & $\begin{array}{l}95 \% \text { Confidence } \\
\text { interval }\end{array}$ & p value \\
\hline Log-likelihood $=-217.73, \chi^{2}=62.15, \mathrm{p}<0.001$ & & & & \\
& & & & \\
Medical/surgical examinations in the ED & 2.82 & 0.69 & $1.75-4.57$ & $<0.001$ \\
Number of investigations in the ED & 4.41 & 1.84 & $1.95-10.01$ & $<0.001$ \\
Speed velocity when the accident occurred & 1.02 & 0.01 & $1.01-1.03$ & $<0.001$ \\
Age & 1.03 & 0.01 & $1.01-1.04$ & 0.011 \\
Implementation of the new traffic code & 0.51 & 0.16 & $0.28-0.94$ & 0.03 \\
Time of the accident & 1.34 & 0.43 & $0.72-2.5$ & 0.357 \\
Road classification & 4.41 & 1.84 & $0.45-1.37$ & 0.391 \\
\hline ED, emergency department. & \multicolumn{5}{l}{} \\
\hline
\end{tabular}

their behaviour is being assessed for important reasons, the self-reporting method is generally considered reliable. ${ }^{56}$

An important finding of our survey is that $27.4 \%$ of the drivers who presented at the emergency department had conditions defined as non-urgent-that is, conditions requiring interventions that could be provided at more appropriate care centres, without the need for referral to a highly specialised ED. Our study included only the drivers who survived and, therefore, not those who died at the scene or en route to the hospital. However, we do not expect a high number of fatal accidents in this area. With regard to the contribution of different factors to the use of the ED as a source of non-urgent care our results indicate that, of the demographic and crash related variables, only the age of the driver and the speed made a significant contribution to the outcome of interest. Younger drivers and those driving at lower speeds were more likely to use the ED as a source of non-urgent care. Although it was not our objective to investigate the association between medical conditions and automobile crashes, the finding that those who are older are more likely to require urgent care is consistent with other studies which report that older people tend to have deteriorating visual, cognitive, and perceptual functions that increase risk ${ }^{7}$ and those with heart disease or stroke are more likely to be involved in crashes. ${ }^{8}$ Furthermore, the higher the speed the higher the fatality rate. ${ }^{10}$ The number of consultation activities undertaken in the ED was related to its use, since those who underwent fewer diagnostic investigations and who did not undergo any medical/surgical examination were more likely to use the ED as a source of non-urgent care. As revealed in previous studies, the adoption of similar laws worldwide enforcing the use of car seat belts has contributed to a concurrent decrease in serious and fatal injuries. In our study also attendance for nonurgent care to the ED was significantly higher before the implementation of the new traffic code..$^{11}$
Almost all crashes reported by the victims in this study involved no major injuries and yet, almost half tended to be collisions. Although we did not ask directly whether these victims were involved in litigation or whether they intended to pursue compensation via lawsuits, we are confident that our finding of the large non-urgent use of hospital services may be explained by the trend to attend hospital for legal implications. This is supported by the higher prevalence of non-urgent access reported in this survey than in a previous study (conducted by some of us in the same area). That study reported a lower percentage of non-urgent problems, 19.6\%, in patients aged 15 years or older who attended the ED because they believed their problem was an emergency. ${ }^{13}$ Another explanation for the high number of non-urgent visits is that only $10.8 \%$ of the patients were brought to the hospital by ambulance. Indeed, when an ambulance is called, the ambulance doctor assesses the severity of the case, provides first aid to stabilise the patient's physiological functions, registers the sudden loss of function of an organ or system, and eventually communicates to the ED that a patient with a serious health status is arriving. However, it should be pointed out that in the Italian healthcare system, EDs provide 24-hour availability of services, its use by victims of road accidents is free of charge, and generally we do not have minor injuries units separate from the ED. Finally, although all patients have a general practitioner, available only during office hours, who provides primary care and plays a vital role in medical emergencies in public healthcare system, our data indicate that the ED is often used as a source of primary health care.

It was not the purpose of our study to record the prevalence of use of seat belts while driving at the moment of the accident, yet we found that $80.4 \%$ of the sample were using seat belts at the time of the accident. This is considerably higher than the $44.6 \%$ of drivers involved in motor vehicle crashes in the USA ${ }^{14}$ and $62.6 \%$ of car occupants injured in a

Table 4 Classification of the injuries according to body region and nature of the worst injury

\begin{tabular}{|c|c|c|c|c|c|c|c|c|}
\hline & Head & Neck & Thorax & $\begin{array}{l}\text { Abdomen, pelvis, } \\
\text { and lower back }\end{array}$ & $\begin{array}{l}\text { Upper } \\
\text { extremity }\end{array}$ & $\begin{array}{l}\text { Lower } \\
\text { extremity }\end{array}$ & $\begin{array}{l}\text { Multiple body } \\
\text { regions }\end{array}$ & Number (\%) \\
\hline Pain & & 96 & 1 & 18 & 2 & & 5 & $122(28.8)$ \\
\hline Abrasion & 1 & & & & & 2 & 5 & $8(1.9)$ \\
\hline Contusion & 11 & 10 & 20 & 13 & 27 & 22 & 41 & $144(34)$ \\
\hline Open wound & 13 & 1 & & & 1 & 1 & 1 & $17(4)$ \\
\hline Fracture & 7 & 1 & 5 & 2 & 8 & 5 & 1 & $29(6.8)$ \\
\hline Dislocation, sprains, and strains & & 78 & & 3 & 6 & 10 & & 97 (22.9) \\
\hline Injury to internal organs & & & 1 & 2 & & & & $3(0.7)$ \\
\hline Loss of consciousness & 4 & & & & & & & $4(0.9)$ \\
\hline Number (\%) & $36(8.5)$ & $186(43.9)$ & $27(6.4)$ & $38(8.9)$ & $44(10.4)$ & $40(9.4)$ & $53(12.5)$ & $424(100)$ \\
\hline
\end{tabular}


traffic accident seen in a prehospital first aid centre in Brazil. ${ }^{15}$ Our finding is similar to the percentage of belted drivers $(77.5 \%)$ seriously injured in automobile crashes in data from police reports over a 10 year period ${ }^{16}$ and lower than the $90 \%$ reported in a retrospective review of 100 consecutive patients presenting with chronic neck pain after road traffic accidents in Ireland. ${ }^{17}$ Moreover, a considerable increase in the use of this safety device-from $47.7 \%$ to $91.7 \%$-was reported after the implementation of the new traffic code. One of the reasons for this finding was a promotional campaign educating Italian citizens about road safety that emphasised the use of seat belts and described the dangers without one. Another is that the police is now less lenient towards traffic code law-breakers and no longer ignores those drivers who do not use them. This finding is in accordance with previous studies, in that adoption of similar laws worldwide has contributed to increased seat belt use. ${ }^{11}{ }^{15}{ }^{18}$ We must stress, however, that even after the new legislation came in force, a high proportion, $8.3 \%$, still refused to heed the law. This unexpected finding is worthy of further study to identify reasons why people refuse to comply with safety regulations despite mandated legislation.

In conclusion, development of health promotion and education campaigns is required to prevent the use of the $\mathrm{ED}$ as a source of non-urgent care by those involved in automobile accidents.

\section{CONTRIBUTORS}

C Pileggi and G Nicotera participated in designing the study, and collected the data and contributed to the data analysis and interpretation. I F Angelillo, the principal investigator, designed the study, was responsible for the data analysis and interpretation, and wrote the article.

\section{Authors' affiliations}

C Pileggi, G Nicotera, I F Angelillo, Chair of Hygiene, Medical School, University of Catanzaro "Magna Græcia", Catanzaro, Italy

Competing interests: none declared

\section{REFERENCES}

1 ISTAT (Istituto Nazionale di Statistica). Statistica degli incidenti stradali. Roma: Anno, 2002. Available at: http://Catalogo.isat.it/20031023_00/ (accessed 8 January 2004).

2 Legge 1 agosto 2003, n.214. Conversione in legge, con modificazioni, del Decreto Legge 27 giugno 2003, n. 151, recante modifiche ed integrazioni al codice della strada. GU 12 agosto 2003, n. 186.

3 Larsen CF. The value of CD-10 in producing AIS information. In: Rogmans WHJ, Mulder S, eds. Measuring the severity and costs of accidental injuries. Amsterdam: ECOSA, 1998.

4 Beveridge R, Clarke B, Janes L, et al. Canadian Emergency Department Triage and Acuity Scale: implementation guidelines. Can J Emerg Med 1999;1(suppl. 3):S1-S28, Available at: www.caep.ca/002.policies/002-02.ctas.htm (accessed 7 April 2003)

5 Oppenheim AN. Questionnaire design, interviewing and attitude measurement, 2nd edn. London: Pinter, 1992.

6 McColl E, Jacoby A, Thomas L, et al. Design and use of questionnaires: a review of best practice applicable to surveys of health service staff and patients. Health Technol Assess 2001;5:22-3.

7 Owsley C, Ball K, McGwin G Jr, et al. Visual processing impairment and risk of motor vehicle crash among older adults. JAMA 1998;279:1083-8.

8 McGwin G Jr, Sims RV, Pulley L, et al. Relations among chronic medical conditions, medications, and automobile crashes in the elderly: a populationbased case-control study. Am J Epidemiol 2000;152:424-31.

9 Ossiander EM, Cummings P. Freeway speed limits and traffic fatalities in Washington State. Accid Anal Prev 2002;34:13-18.

10 Bartle ST, Baldwin ST, Johnston C, et al. 70-mph speed limit and motor vehicular fatalities on interstate highways. Am J Emerg Med 2003;21:429-34.

11 Rivara FP, Thompson DC, Cummings P. Effectiveness of primary and secondary enforced seat belt laws. Am J Prev Med 1999;16:47-56.

12 Redelmeier DA, Tibshirani RJ, Evans L. Traffic-law enforcement and risk of death from motor-vehicle crashes: case-crossover study. Lancet 2003;361:2177-82.

13 Bianco A, Pileggi C, Angelillo IF. Non-urgent visits to a hospital emergency department in Italy. Public Health 2003;117:250-5.

14 Nelson DE, Bolen J, Kresnow M. Trends in safety belt use by demographics and by type of State safety belt law, 1987 through 1993. Am J Public Health 1998;88:245-9.

15 Liberatti CLB, Andrade SM, Soares DA. The new Brazilian traffic code and some characteristics of victims in southern Brazil. Inj Prev 2001;7:190-3.

16 Mayrose J, Jehle DV. An analysis of race and demographic factors among motor vehicle fatalities. J Trauma 2002;52:752-5.

17 Kim S, Kim K. Personal, temporal and spatial characteristics of seriously injured crash-involved seat belt non-users in Hawaii. Accid Anal Prev 2003;35:121-30

18 Mulhall KJ, Moloney M, Burke T, et al. Chronic neck pain following road traffic accidents in an Irish setting and its relationship to seat belt use and low back pain. Irish Med J 2003;96:53-4. 